\title{
Building An Entrepreneurial Economy: Evidence From Developing Countries
}

\author{
Mohamed Imam Salem, King Saud University, Kingdom of Saudi Arabia
}

\begin{abstract}
Entrepreneurship contributes to economic development in all countries all over the world and has always been a powerful driving force of innovation, productivity, job creation and economic growth. In recent years, the Kingdom of Saudi Arabia has launched a broad range of intensive and creative initiatives to kick-start entrepreneurship, to further promote a business climate that supports innovation and competitiveness, and to inspire the next generation of company builders. Prior studies have not given much attention to the entrepreneurial role that universities play in building entrepreneurial economies, especially in the Arab World.

This paper attempts to address the research gap relating to the process by which universities can foster a culture of entrepreneurship in the Kingdom of Saudi Arabia. One major challenge is to develop contents and methods that encourage entrepreneurial learning. The paper confirms that entrepreneurship education can help promote an entrepreneurial and innovate culture by changing mindsets and providing the necessary skills. In this way, universities have become increasingly important for national and global economic development.
\end{abstract}

Keywords: Entrepreneurship; Economic Development; Economic Growth; Universities; Innovation; Saudi Arabia

\section{INTRODUCTION}

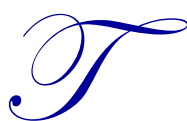

he convergence of globalization, technological innovations and knowledge-based economies, and demographic trends has led to an increased focus on the effects and importance of entrepreneurship. In this context, entrepreneurship is a driving force of economic development, structural change, and job creation. It is also a way to address the challenge of poverty reduction (World Economic Forum, 2009).

Szirmai (2011) argues that entrepreneurs are usually people characterized by high intelligence, high selfesteem increasing the sense of one being in control of their future, and they have the capacity to start and run businesses. Being an entrepreneur needs one to take an added step, which is usually time-consuming and expensive and, according to recent studies by scholars, they engage more in risk-taking activities (Eugenia, Aikaterini, \& Lida, 2009). Most successful entrepreneurs are aggressive and, as a result, they tend to earn more per hour compared to employed persons. Critical thinking is necessary for the success of any entrepreneurial idea to become a success. With mentors, innovations become more frequent since this offers experiential lifelong learning, founding the awareness of personal culture (Vassilis \& Errikos, 2012). Liberal arts, writing skills, and strong leadership skills help one to capitalize on available opportunities with readiness to face cultural, environmental, and economic challenges in the environment. Personal growth is enhanced through formal and experiential learning and this is a key factor that contributes to successful entrepreneurial projects.

Entrepreneurial activities are great contributors to the growth of economies through the wealth gained by business-minded persons. Exposure to the business environment enhances one's opportunity to engage in creative freedoms. Educators and economists believe that by imposing certain cultures in the society, it can help individuals maximize on the collective social and economic success (Potter, 2008). With this in mind, entrepreneurship education was developed to help both youths and adults succeed in an entrepreneurial economy. This begins at an early age in elementary school until one is an adult. Institutions use the appropriate framework, assessment, and learning activities to support performance of the scholars, even in challenging activities and opportunities (UNIDO, 
2003). This instills the learners with insight to discover and establish entrepreneurial opportunities, taking full advantage of them. By imparting such knowledge to scholars, this also helps in increasing their employability in the job market, both local and international (Sandler, 2009).

Entrepreneurial education increasingly continues to unleash the entrepreneurial and innovative capabilities by stimulating young minds into exploiting the entrepreneurial potentials. Education not only enhances an individual's competence, but it also gives one the ability to plan and manage projects, even in the day-to-day activities at home and in society. Entrepreneurial education seeks to enhance the mindsets of young people with creativity and self-competence, promoting the making of realities of innovative ideas and promoting the involvement of the young in the society and economic success. With entrepreneurial learning on the increase, it also faces several challenges including funding and unsustainable human resources for the education (Potter, 2008).

According to Eugenia, Aikaterini, and Lida (2009), entrepreneurship education in higher learning programs continues to be of importance to both individuals and the general society since it helps both achieve a more fulfilled life. Persons under such programs acquire attitudes that enable them to take action in taking responsibility of their life, career, and learning. Certain personal characteristics acquired build on one's self-efficacy, risk propensity, and structural behavior for perseverance when facing obstacles. Business running skills are also attained together with the capacity of an individual's creativity, motivating, networking, and adaptability, to handling different situations with ease (Szirmai, 2011). Broader understanding and knowledge that is quite essential in running programs under the new economy is also acquired.

\section{ENTREPRENEURIAL LEARNING: OPPORTUNITIES AND CHALLENGES}

Most higher learning institutions and universities have not fully integrated the entrepreneurship programs in their curricula and they continue to be offered only in business and economic studies. With continued development of an individual's competence, there are greater chances of getting better-paid jobs. The economies in most societies are likely to improve if the individuals are more willing to take entrepreneurial initiatives. The competencies are enhanced through learning programs promoting the role of the individual in enhancing the economy (Potter, 2008).

The social and personal life is, to some extent, affected by the entrepreneurial learning programs, and this affects the complete societal relations and activities. New jobs and new enterprises that are set up within the societies influence the economy through the annual growth rates, innovation levels, and employment (Eugenia, Aikaterini, \& Lida, 2009). The programs may also incite persons to take part in voluntary works within society, which may be in schools, politics, and environmental volunteering. Starting non-commercial projects also provides an environment where persons can bring their energies together in order to achieve a common good for the society. Incomes earned help in assisting to reduce the poverty levels in society and, if re-invested, this offers employment opportunities as well as more revenues (Sandler, 2009). Business enterprises that are set up enhance the production of commodities within reach of consumers and enhance the access of services to the people in the society.

The contemporary university has incorporated entrepreneurial aspects which is a critical factor in enhancing the development of modern economies. This academic revolution aims at socio-economic development through teaching and research (Vassilis \& Errikos, 2012). The scholars from these institutions learn relationshipbuilding, risk-taking, problem-solving, and have access to mentorship programs. They also have opportunities to mix life experiences with transferable skills and formal education, which greatly shapes the transition of their abilities to existing projects. Self-employment brings more certainty compared to employment that comes along with uncertainties. Self-employment offers security and stability to individuals and it does not always have to give fixed incomes, a working environment, and the state of stability with employment. Graduates have high employability chances due to high experience and creativity, which determines one's chances of satisfaction with their current job positions. The main challenge for the institutions, as identified, is the difficulty of building interdisciplinary approaches for all other courses. The increasing demands of the entrepreneurial studies face the problem of too few professors to teach under the program. There is need for more support on the enabling and drawing more human resources in the teaching of this type of education.

The governments need to do more in terms of passing incentives as a way of motivating more persons to take part in entrepreneurial studies. More funds should also be directed toward the projects which can enhance 
research and the equipping of institutions with the needed resources and materials. With this, more scholars may be motivated to join the studies and institutions may also be motivated to deliver entrepreneurship. Vassilis and Errikos (2012) further state that the availability of funds can enhance the distribution of the programs to different study levels, including undergraduate, graduate, post-graduate, and even $\mathrm{PhD}$ groups. This can be more effective if such education is offered to the relevant technical areas with several workable examples. With the current modes of teaching, there are several ways of delivering to scholars, especially by supplementing lectures. This includes direct interactions with scholars and involving real entrepreneurs since they have practical experience. Mobility of teachers and researchers should be actively encouraged (Potter, 2008).

Public authorities should set up departments or a task force to determine how these programs can effectively be integrated in the different levels of education. Relations between businesses and universities should also acquire support in order for both to integrate their concepts of theory and practical ideas. Non-formal learning programs also enhance the possibility of educating people on entrepreneurship development; therefore, this should not be set aside. Students, teachers, and universities can establish an awards system as a way of promoting positive academic spin-offs. The higher education institutions themselves should set up plans of action and strategies on how to conduct effective teaching and research programs to its scholars (UNIDO, 2003).

Students should be given opportunities to attend seminars and outdoor lectures, which can also be accompanied by an introduction to self-employment for all undergraduates during their first years. The institution should also bring up an awards system for acknowledging the staff for supporting scholars as a way of motivating the entrepreneurial field. To add to that, entrepreneurial education has been known for its effect of increasing one's intentions of becoming entrepreneurs (Eugenia, Aikaterini, \& Lida, 2009). Most self-employed persons are those with higher urges of being independent and having the freedom of time and place in the realization of business opportunities. Clear rules on the conduct of the institution should also be laid down. On the issue of other stakeholders in the enterprise, associations can be established to build educational establishments such as training of teachers in different nations and promoting other cross-border programs.

The issue of globalized education for entrepreneurship programs continues to be integrated in the academic systems of most countries, though it only seems positive in a few of the countries. Research conducted showed that these programs have been most successful when offered under business and economic studies (UNIDO, 2003). Among the many countries that have continued to record positive transition are those that have instilled the program into its system. Experts argue that the successful countries also experienced changes in the security levels due to the involvement of the youth in useful activities, hence reducing the numbers of idle youths who, at most times, end up engaging in crime. Research confirmed that entrepreneurial activity is likely to be low in states that have adopted less courses related in business. This initiative on entrepreneurial learning enhanced the aspect of self-employment to both undergraduates and graduate students. Most of the universities in Belgium, for example, adopted this notable initiative and offered entrepreneurial studies as an introductory course to all studies (Potter, 2008).

In the republic of Czech, entrepreneurial studies are taught within technical counterparts, though with limits since it is not closely related to economics and business. Technology has also been linked up with courses on entrepreneurship, hence promoting the marketability of the scholars. In addition, Denmark enjoys the support by the government, and this has enhanced the growth of technical studies, economic, and humanistic programs. This has been made stronger through policy plans and legislations. Similarly, Germany, Ireland, Greece, Spain, Italy, and Cyprus have all shown their devotedness to placing entrepreneurial studies in the higher learning programs for potential entrepreneurs in fields like management, economics, industrial engineering, and other related courses (OECD, 2011). Other initiatives between these countries have been established to enhance exchange programs, training, and research programs among the members. The United Kingdom government has supported these initiatives through funding for the higher learning institutions. This has enhanced the development of enterprises enhancing the involvement into supply and demand market forces. Estimations done show that 95 percent of higher learning institutions in the United Kingdom engage in offering entrepreneurship education to their students.

Organizations have come up in the less developed areas to support rural people and women for entrepreneurial initiatives. People living in the rural areas shoulder the burden of poverty mostly in less developed states. Sub-Saharan Africa is deprived of the benefits of economic growth and globalization and this has resulted to 
the continued disparities and gender inequalities (UNIDO, 2003). These countries need to invest in improving the institutional and human capacities to enhance the sprout of economically gainful initiatives in the region. Poverty in these areas needs to be approached from a multi-dimensional approach, like the bottom-up growth strategy. The government in these areas also focuses on strengthening entrepreneurial capacities through entrepreneurial studies in higher learning institutions and universities. The government also insists on the creation of an enabling business environment and promotion of collective self-help efforts for young upcoming entrepreneurs. Before undertaking any projects, the organizational bodies focus on strategic focus, people-centered, root-cause analysis, gender sensitive, locally specific, asset-based, analyze the absorptive capacities, and sustainability of the projects.

These countries include Kenya, Morocco, and Vietnam, among others. In Uganda, the government encouraged the establishment of vocational schools to help students acquire technical skills. The Ministry of Education in the country has also provided funding for academic materials and has introduced business-related courses into the systems at reduced costs.

Entrepreneurial education in higher learning institutions and universities focuses on, first, entrepreneurial motivation. Individuals learn of the social and economic importance of engaging in profit-making activities with the use of scientific and technological information. Secondly, it helps people realize and be able to recognize opportunities and have the courage to pursue it. The involvement of practitioners in lectures enhances the subject of commercialization in different situations. The key aim by the institutions remains to be enabling the capacity of scholars in creativity, innovations, self-confidence, self-realization, and the capacity to handle challenges. Effective communication, proper decision-making, good negotiating skills, systematic thinking, proper networking, and leading skills are also necessary skills that enhance the success of entrepreneurs. According to the United Nations Industrial Development Organization (2003), all fields and courses in entrepreneurship can be linked to the specific needs of the different categories; for example, in science and technology, there is the unending urge to create spinoff companies and venturing. This may result to the learning of management techniques, marketing, commercializing, patenting, and protecting technology based ideas, financing, and inter-nationalizing high-tech ventures. Humanities fields can focus on self-management and social entrepreneurship in order to help achieve a change in the societal economic progress (Potter, 2008).

According to the United Nations Industrial Development Organization (2003) in the United States, innovations have had a great impact on the well-being of the domestic economies. Information technology in the country has also enhanced fragmentation of the innovation process. The continued emphasis on entrepreneurial education by the United States government helps ensure that more innovations continue to be tailored to the local demand. For the countries that have not yet developed, their future is determined through the interest of students wishing to work with technological, development, and globalization sectors. Globalization in the modern society demands that new generations should be instilled with knowledge and skills to help them work in the different cultural regions and under different organizations. There is also increased activity between local organizations and oversees organizations in an attempt to enhance the exchange of ideas, knowledge, and even skills, all aimed at enhancing the entrepreneurial and innovative capacities of the population. The ability for an individual to function across different nations and culture enhances their employability capacity (Szirmai, 2011).

An article by Vassilis and Errikos (2012) states that the government and educational institutions have increased their attention to the upcoming trends on entrepreneurial education, as well as globalization, that has resulted to changes in the world economy. The main aim among these institutions is to enhance the creativity of learners with the increasing demand for business and entrepreneurial skills in the globe due to the globalization trends. The aspect of globalization adds a new paradigm to all aspects of creativity, knowledge, and competition. Nations can only fit in the global market if it develops on its knowledge and human capital on the global standards of ethics. The job opportunities for college graduates are increasingly on demand, and this is a catalyst for enhancing economic growth (OECD, 2011). It serves as a platform for countries to maintain their competitiveness in the face of globalization. Globalization has significantly affected the demand trends in business and entrepreneurial education since it cannot be suppressed. 


\section{THE PRINCE SALMAN ENTREPRENEURSHIP INSTITUTE (PSEI)}

The Kingdom of Saudi Arabia (KSA) is the world's most important oil producer, with revenues reaching up to 75 percent of its total budgetary revenues and export oil revenues accounting for 90 percent of its total exports. This means that KSA's economy is natural resources based. However, recently there has been a call by the government to diversify the country's economy, utilizing numerous resources to achieve this goal.

Realizing the true need to diversify the economy, the Ministry of Higher Education has focused its resources on the improvement and development of the human capital of its citizens by opening over 65 universities and colleges since 1957. In addition, annually the Ministry sends thousands of its students to study abroad. Leading universities in the Kingdom have stepped up to do their part toward this ambitious goal. In 2011, the Prince Salman Entrepreneurship Institute at King Saud University has performed a leadership role with their First International Forum for Entrepreneurship and Knowledge-Based Economy. All these efforts are aimed at raising the skills and talent level of the next generation of graduates and preparing them to contribute to the knowledge-based economy and, hence, diversifying the country sources of wealth. The effort to catch up with the developed world is commendable, but missing critical steps to leapfrog forward.

To achieve its economic diversification goals, KSA needs to make the promotion of entrepreneurship and innovation culture and education a paramount priority. It is well known that entrepreneurship - especially the technology-based kind - is the primary driver of economic growth in the fastest developing countries. It is widely recognized that competitiveness, innovation, and economic growth depend on being able to produce future leaders with the skills, attitudes, and behaviors to be entrepreneurial and to act, at the same time, in a socially responsible way. Entrepreneurship is not only about creating business plans and starting new ventures. It is also about creativity, innovation, and growth - a way of thinking and acting relevant to all parts of the economy and society (World Economic Forum, 2009). The question then is how to introduce entrepreneurship education in the curriculum at Saudi universities?

The Prince Salman Entrepreneurship Institute (PSEI) is one of the modern institutes established by King Saud University (KSU) as a unique initiative added to other university developmental initiatives to contribute to building knowledge and sustained development culture in society in harmony with the development trends of the Ministry of Higher Education toward the elevation and progress of higher education. The institute was established in 2008. With its stated vision to be one of the best ten international institutes by the year 2020 in building a culture of entrepreneurship and supporting entrepreneurs and a mission to create the knowledge-based economy and encourage entrepreneurs to convert their innovative ideas into new ventures, PSEI represents an important addition to the growing number of initiatives that the KSA is implementing as a means of broadening its future economic growth away from petroleum-based activities.

Today, academics are leading their own way towards an educational style that interacts positively with applied and practical cases and moving as intellectual pioneers to facilitate transfer of knowledge and technology with focus on applied research. Based on the university's sincere endeavor to contribute to building knowledge and sustainable development culture in society in order to build a distinguished generation of students in the various creative and innovative fields of knowledge economy, this ambitious institute is taking its leadership role.

The importance of the institute, as the first entrepreneurship institute at Saudi universities, stems from its being the network complementing the university's distinction and pioneering role. In addition, the institute is the university's tool in supporting the concept of an entrepreneurial university. It seeks to have strong sustainable strategic relationships with the business sectors in the Kingdom. The institute also enhances the principle of global partnership with unique universities to transfer and benefit from their experiences, enrich the academic programs of the university, and bridge the gap between education and application to shift the university toward the desired knowledge-based economy. The institute is looking forward to effective partnership and participation with national organizations, society entities, and businessmen to enhance the mission of the institute and achieve its ambitious goals.

To achieve its stated vision, the institute adopts the following values: 1) social responsibility through initiating innovative ideas, entrepreneurial initiatives, and creative thinking to support building of knowledge-based 
economy, 2) response to the needs of entrepreneurs through flexible business policies and systems to support the entrepreneurial activities, 3) positive interaction with local and global factors and events to improve quality and efficiency of the institute's initiatives, 4) professional commitment to updating and developing the institute's activities and services through a positive business environment that motivates innovation and creativity, 5) continual improvement of the institute's capabilities and potentials to develop its own resources to support its role, 6) continual enhancement of excellence in service delivery, and 7) effective communication with strategic alliances to facilitate the institute's interactions with the outer world.

As already outlined by its First Strategic Plan (2011-2016), the institute seeks to achieve the following strategic goals: 1) to participate in building of a knowledge society and knowledge-based economy aligned with development goals and plans of KSA, 2) to promote a culture of entrepreneurship and enhance entrepreneurial skills, attitudes, and behaviors among students and graduates to successfully start and manage their ventures, 3) to develop understanding and building knowledge around entrepreneurship in collaboration with relevant stakeholders in society, 4) to actively support the important role that small business ventures play as a key driver in creating new jobs for graduates in the Kingdom, 5) to enhance students' entrepreneurial abilities to find out ideas and turn them into action, and 6) to continuously develop human and technical capabilities of the institute.

The institute's activities focus on five major areas, including teaching, training, consulting, research, and business communication. Accordingly, PSEI has launched a range of initiatives to enhance entrepreneurial activities and behaviors. In this context, the institute aims at recruiting distinguished researchers in the field of entrepreneurship and encouraging academic staff at various faculties to actively participate in entrepreneurship research. This can be achieved through a coordinated research agenda and pooled resources.

The institute plays a key role in success and growth of business incubators, which are hosted by Riyadh Techno Valley for Knowledge located at King Saud University. The institute offers, through its full-time staff as well as the staff of Business Administration Faculty, advice and guidance to young entrepreneurs in the areas of idea screening, market analysis, strategic management, financial planning, and growth strategies.

The Entrepreneurship Association, one of PSEI's initiatives, is the first academic and professional association in the Arab World. It seeks to promote an entrepreneurial culture in society and raise awareness about the importance of entrepreneurship for developing societies. The association provides a hands-on experience in new venture creation to students with sharp minds and a passion for entrepreneurship.

The institute also supports the KSU orientation toward global entrepreneurship. It is evident that international universities have entrepreneurship centers and programs to foster innovation and creativity among students and staff. The institute aims at creating a supportive learning environment for entrepreneurship and it also seeks to have strategic alliances with international universities to promote international networking and cooperation.

\section{CONCLUSION AND POLICY IMPLICATIONS}

The aim of this paper is twofold. First, it explores the factors that contribute to entrepreneurial learning at universities and higher education institutions. Second, it sheds light on the important role that Prince Salman Entrepreneurship Institute plays in fostering a culture of entrepreneurship among students and graduates to engage in entrepreneurial activities.

It is evident that entrepreneurship is a key role player in the enhancement of development for building an innovative culture and creating entrepreneurial individuals. Economic growth is likely to be experienced with the increased business activities and employment that, in turn, enhances an improved standard of living. The Organization for Economic Co-operation and Development (2011) argues that there are, however, predominant challenges in the whole process in changing people's culture and mindsets in different localities. Lack of exposure to the entrepreneurial environment and lack of role models has posed difficulties in achieving the target in developing countries (OECD, 2011). The government should take the key role in promoting development reforms and inciting more partnerships in the sector for promoting scientific and technology curriculums. A research by the United Nations Industrial Development Organization (2003) proved that legislations, incentives, and other 
instruments are necessary to promote mobility between the private and public academic institutions. When analyzing the globalization of innovation and entrepreneurship, it is necessary to balance between cheap innovations, the technological edge, adequate education and funding, and, lastly, a friendly environment with the necessary regulations and policies.

The Prince Salman Entrepreneurship Institute (PSEI) is the first academic entrepreneurship institute in the Kingdom of Saudi Arabia. If it is to position itself as an initiative for innovation-led entrepreneurship that supports new and existing Saudi Arabian-owned and initiated knowledge-based businesses to spur and diversify the economic development of the Kingdom, then PSEI needs to become more than simply an academic institute. It needs to become engaged in fostering ideas and knowledge and then transfer those ideas into business development opportunities. It needs to establish a series of services and programs to support business development, ranging from assisting the individual with ideas, to micro enterprises, and to small- and medium-sized enterprises with the capacity to increase knowledge transfer. Future studies need to focus on measuring the effectiveness of PSEI's services and activities.

\section{ACKNOWLEDGEMENT}

This study is supported by the Deanship of Scientific Research at King Saud University.

\section{AUTHOR INFORMATION}

Mohamed Imam Salem holds a Ph.D. in Economics from Utah State University, USA. He is a faculty member and senior researcher at Prince Salman Entrepreneurship Institute, King Saud University, Saudi Arabia. He has had experience teaching economics and finance at a number of universities in Canada, Egypt, and Saudi Arabia. His research interests include entrepreneurship, knowledge-based economies and economic development. Dr. Mohamed maintains an active consulting practice. E-mail: miisalem@ hotmail.com

\section{REFERENCES}

1. Acs, Z. J. (2006). How is entrepreneurship good for economic growth? Innovations, I(1), 97-107.

2. Acs, Z. J., Desai, S., \& Hessels, J. (2008). Entrepreneurship, economic development and institutions. Small Business Economics, 31, 219-234.

3. Eugenia, P., Aikaterini, S., \& Lida, P. (2009). Entrepreneurship education in higher educational institutions: The gender dimension. Gender in Management: An International Journal, 24(4), 286-309. Retrieved from http://www.emeraldinsight.com/journals.htm?articleid=1793533

4. Organisation for Economic Co-operation and Development. (2011). State of Penang, Malaysia 2011. Paris: OECD.

5. $\quad$ Potter, J. (2008). Local economic and employment development program. OECD. International Government Publication.

6. Sandler, M. R. (2009). Social entrepreneurship in education: Private ventures for the public good. Lanham: Rowman and Littlefield Education.

7. Prince Salman Entrepreneurship Institute. (2011). Strategic Plan (2011-2016). Kingdom of Saudi Arabia: King Saud University.

8. Szirmai, A. (2011). Entrepreneurship, innovation, and economic development. Oxford: Oxford University Press.

9. United Nations Industrial Development Organization. (2003). A path out of poverty: Developing rural and women entrepreneurship. Vienna. Retrieved from http://www.unido.org/fileadmin/user_media/ Publications/Pub_free/A_path_out_of_poverty.pdf

10. Vassilis, K., \& Errikos, S. (2012). Investigating higher education graduates' entrepreneurship in Greece. Annals of Innovation \& Entrepreneurship: Original Research Article, 3(2012). Retrieved from http://www.innovationandentrepreneurship.net/index.php/aie/article/view/17291/html

11. World Economic Forum. (2009). Educating the next wave of entrepreneurs: A report on the global education initiative. Switzerland. 
NOTES 